\title{
Developing optimized prioritizing road maintenance
}

\author{
Hussein Ali Ewadh ${ }^{1, *}$, Raid Almuhanna ${ }^{2}$, and Saja Alasadi ${ }^{2}$ \\ 1College of Engineering, University of Babylon, Hilla, Iraq \\ ${ }^{2}$ College of Engineering, University of Karbala, Karbala, Iraq
}

\begin{abstract}
Increased demand for efficient maintenance of the existing roadway system needs optimal usage of the allocated funds. The paper demonstrates optimized methods for prioritizing maintenance implementation projects. A selected zone of roadway system in Kerbala city represents the study area to demonstrate the application of the developed prioritization process. Paver system PAVER integrated with GIS is used to estimate and display the pavement condition index PCI, thereby to establish a priority of maintenance. In addition to simple ranking method by PCI produced by the output of PAVER, the paper introduces PCI measure for each section of roadway. The paper introduces ranking by multiple measures investigated through expert knowledge about measures that affect prioritization and their irrespective weights due to a predesigned questionnaire. The maintenance priority index (MPI) is related to cost of suitable proposed maintenance, easiness of proposed maintenance, average daily traffic and functional classification of the roadway in addition to PCI. Further, incremental benefit-cost analysis ranking provide an optimized process due to benefit and cost of maintenance. The paper introduces efficient display of layout and ranking for the selected zone of roadway system based on MPI index and incremental BCR method. Although the two developed methods introduce different layout display for priority, statistical test shows that no significant difference between ranking of all methods of prioritization.
\end{abstract}

\section{Introduction}

There is increase demand for new construction as well as efficient rehabilitation and maintenance of the existing roadway system. To preserve the investment spent on this huge network of pavement, extensive maintenance and repair activities are necessary, with the intention of using funds optimally [1]. Accordingly, for some nation's interstate highway system in developed countries as well as for the case of restricted budgets in developing countries, the focus is shifting from new construction to maintaining, preserving, and rehabilitating highway assets. However, the resources made available for road maintenance are limited in most countries [2].

According to the World Bank Report, "The developing countries have lost precious infrastructure worth billions of dollars through the deterioration of roads. The cost of restoring these roads is going to be three to five times greater than the bill would have been for timely and effectively maintenance", hence there is a need to manage the network more efficiently in a scientific manner [3].

The Pavement Maintenance \& Management Systems (PMMS) have a two main components; first one, all importance's database are identify, such underway and historical information on pavement condition index, pavement structure layer, and traffic value. The second component is a collection of tools that allows us to identify current and future pavement conditions, forecasting financial needs, and identify and prioritize pavement project [3].

The paper demonstrates methods for prioritizing maintenance implementation projects. Due to budget and other constraints, it is believed that site of lowest pavement condition index (PCI) does not always justify maintenance project first.

The term "prioritization" is refer to a review of potential maintenance projects for building and preparation an ordered list of selected sites by maximizing benefits according to budget and other qualification depended on the score of ranking and optimization processes. "Ranking" indicate to an ordered list of projects or project alternatives based on given factors or project benefits and costs.

Prioritization methods presented in this paper are firstly serviceable to developing optimal maintenance projects program across multiple sections of a roadway (in a selected zone) or for an entire roadway system.

\subsection{PAVER and MicroPAVER}

PAVER and Micro PAVER [4] are developed to extend engineers with a systematic process in order to determine maintenance and rehabilitation (M\&R) needs and priorities for pavement management. While Micro PAVER executes on a microcomputer; PAVER is the mainframe version. The PAVER is developed to optimize the use of funds allocated for pavement M\&R.

\footnotetext{
* Corresponding author: ewadh57@yahoo.com
} 
Micro PAVER is utilized to manage all types of driveway (roads, streets), parking lots, and airfield pavement. The PAVER system is depended on the PCI survey and evaluation procedure. also, needs to create of a database in the network inventory to performed network and project analysis, the last one expand the users with detailed of current PCI survey information, possible alternatives for M\&R. It is used for current year or near term needs. Network analysis which is used for forecasting long-term M\&R needs supply the users with the future PCI, budget planning and project priorities. The PAVER system is written in FORTRAN and $\mathrm{C}$ languages and design reside in IBM or compatible with personal computer [5]. The PCI is an evaluation process that is determined according to the procedures included in ASTM D 5340, Standard Test Method for PCI Survey. This procedure is used worldwide to provide a measurement of the condition of pavements taking into account the functional performance with effects of structural performance. cyclic PCI definitions on the same pavement will appear the deferent in performance level with time. The PCI ranges of 0 "Failed" to 100 "Excellent", with an "Excellent" condition equivalent to a pavement at the starting of its life cycle, and a "Failed" condition equivalent to a severely deteriorated pavement without virtually remaining life.

\section{Maintenance priority}

After application of PAVER, a list of pavement condition for the network sections is prepared. In most cases, limited financial resources make it impossible to perform all sections of low pavement condition indices. in the list. funding needs more than available funding. When this happens, one of the methods for prioritizing and optimizing will be needed in order to prepare a maintenance and rehabilitation program. The following is a list of methods for establishing priorities; however, alternate methods can be developed based on an agency's policies and administrative decisions [6].

- The matrix method can be depended on many factors such as traffic and condition; i.e., the pavements in the worst condition and has a heaviest traffic is given the highest priority.

- The condition index method can be depended on relative scores which ranked from 0 (for worst) to 100 (for best). In order to develop a final list of projects, Priorities can combine condition score with many factors such as traffic or functional class.

- In the benefit-cost ratio process, the sections would have the highest priority when it has the highest benefitto-cost ratio. Whereas the previous methods are likely to favor a "worst-first" policy, the benefit-cost rationale can provide high priorities for pavements in fair-to-poor condition rather than always starting with the pavements in the worst condition.
- The cost-effectiveness procedure is the same to benefitcost except that the function is to maximize the performance of the sections while considering cost. Performance, in this case, is a measure of the effectiveness of a particular strategy on a segment over time. Each segment in the agency's network can then be ranked against each other to arrive at a list of maintenance and rehabilitation options. This method does not require a "worst first" approach.

- The maximum benefits procedure is inherent in most optimization methods. This methods can also be developed with life cycle costs and prioritization. For example, that set of projects from all candidate projects, which maximizes the combined benefit-cost ratio or cost effectiveness for a specific budget, would be selected for M\&R treatments. In this research a set of maintenance prioritization methods are proposed to achieve efficient alternatives to maximize cost effectiveness for a limited financial resource.

\section{The proposed maintenance prioritization methods}

Three prioritization methods are proposed in this research as follows:

1) Simple ranking by PCI measure.

2) Ranking by multiple measures.

3) Incremental benefit-cost analysis ranking

Simple ranking by PCI measure provides a prioritized list of projects depended on a pavement condition index criterion. Other measures in addition to PCI are included in the process of ranking by multiple measures. Investigation of expert knowledge about measures that affect prioritization of sites for maintenance is achieved through a predesigned questionnaire. The irrespective scores of each measure and its importance are also investigated. Ranking by multiple measures is improved alternate for condition index method and the matrix method developed by Washington State Department of Transportation.

Further, incremental benefit-cost analysis ranking provide an optimized process of ranking by taking PCI measure as benefit (when maintenance of the roadway section is achieved) and cost of maintenance (according of the suitable maintenance strategy for a specific distress in that section). Hence, this process considers the effect of budget constraints and allocated resources in developing an optimized maintenance project set. Also, this process is related to the benefit-cost ratio process and the cost-effectiveness procedure developed by Washington State Department of Transportation.

\section{Methodology of research}

This study in the done an application of paver system integrated with GIS to establish a priority of maintenance for a selected zone in Karbala city. Due to a restricted budget for a new construction as well as highway demand to maintenance they roadway system, 
the study make use of pavement management existing system to demonstrate the efficient tool of maintenance by PAVER.

A selected zone of roadway system in Kerbala city, represents the study area to demonstrate the application of prioritization process. Karbala is located in the Central Region of Iraq on the edge of the Eastern Plateau Bank, west of the Euphrates River, and specifically between longitudes 43.33 north. A selected zone of urban streets for seven neighborhoods within the CBD area in Karbala city is shown in Figure (1-a). These streets are classified into: major arterial, minor arterial, collector, and local as shown in Figure (1-b). The study area include many activity centers such as; schools, governmental buildings, and religious please.

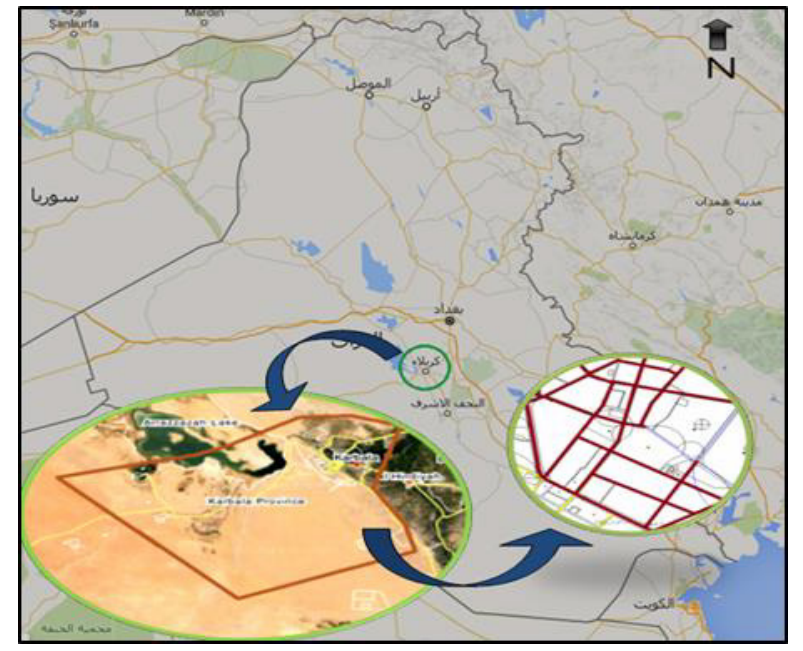

(a)

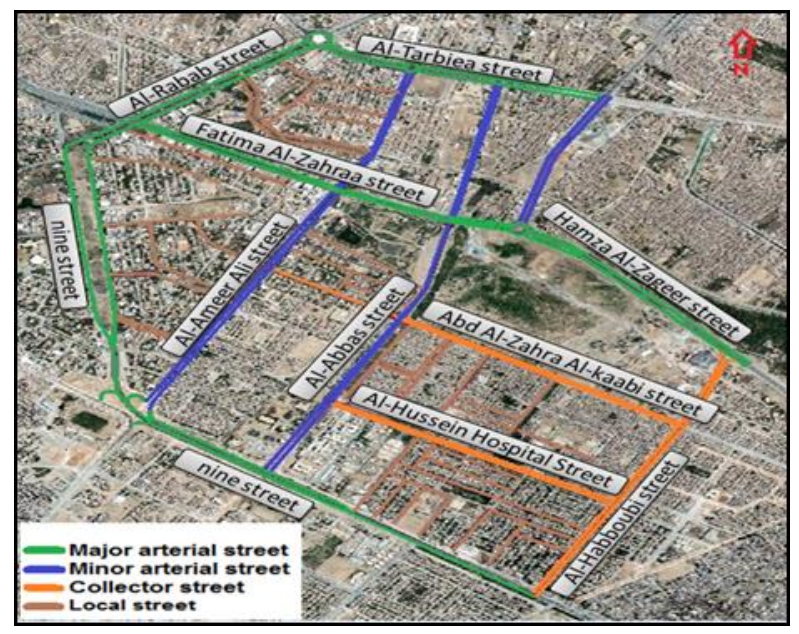

(b)

Fig. 1. The selected zone of road network in Karbala

\section{Application of the proposed prioritization process}

Site inspection is achieved for all sections in the selected zone in the study area. According to the output of
PAVER and other factors affecting pavement condition, the following articles demonstrate the application of the prioritization process.

\subsection{Simple Ranking by PCI Measure}

Simple ranking by PCI depends mainly on the output of PAVER. PCI measure for each section of roadway represents the degree of need to maintenance. Consequently, all sections of the roadway inspected are ranked from lowest PCI to the highest one.

PAVER 6.5.7 allows the pavement manager to maintenance and rehabilitation (M\&R) sections roads and to determine work priorities from the set of critical PCI value. The priority developed afford to the user to limit priorities according to critical PCI value, facility use, or pavement type that used by the M\&R module, to improve a prioritized list of bespoke pavement perfection projects.

The priority typical scale of PCI that can be used to manage M\&R operations is shows in Plate (2). However, users can see the critical PCI to show the behavior of different sections of their pavement depended on their own experience. For example, with a pavement suffering from a high distress rate, crack sealing (preventive maintenance) may not be cost-efficient and therefore the critical PCI value may be adjusted [7].

On the other hand, and depending on PCI values from PAVER output and using GIS tools to layout the maintenance priority for the selected sections as shown in Plate (3).

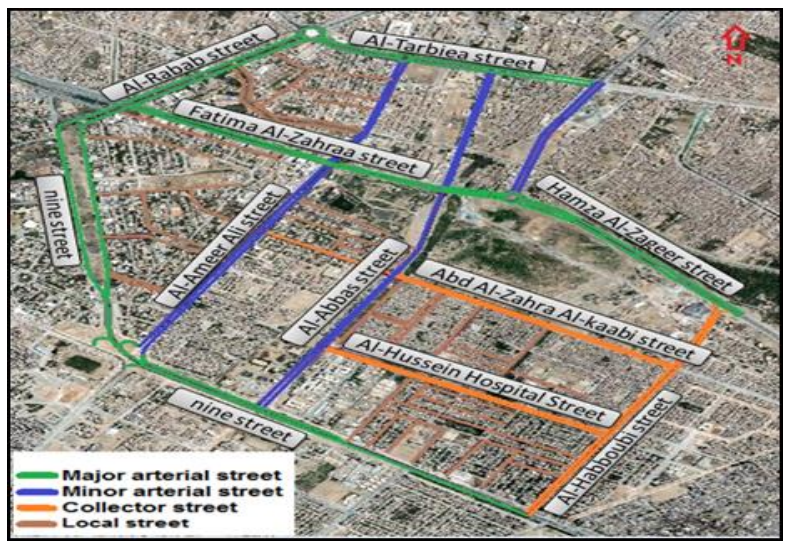

Plate 1.

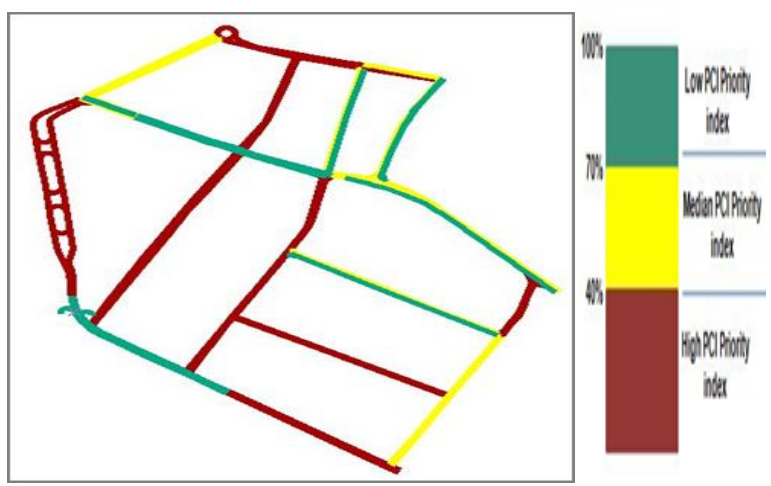


Plate 2. Priority of Maintenance and Rehabilitation for Selected Roadway Zone in Karbala City.

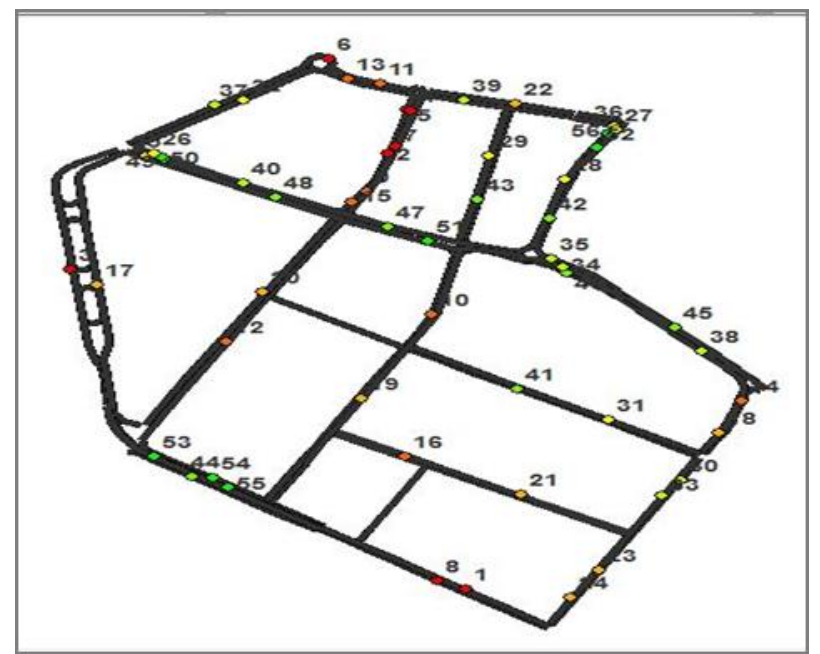

Plate 3. Sectional Maintenance Priority Layouts Due to PCI Values for Selected Roadway Zone in Karbala City

M\&R operations is shows in Plate (2). However, users can see the critical PCI to show the behavior of different sections of their pavement depended on their own experience. For example, with a pavement suffering from a high distress rate, crack sealing (preventive maintenance) may not be cost-efficient and therefore the critical PCI value may be adjusted [7].

On the other hand, and depending on PCI values from PAVER output and using GIS tools to layout the maintenance priority for the selected sections as shown in Plate (3).

\subsection{Ranking by Multiple Measures}

Investigation of expert knowledge about measures that affect prioritization of sites for maintenance is achieved through a predesigned questionnaire. The irrespective scores of each measure and its importance are also investigated. Table (I) sample of the questionnaire are used.

The maintenance priority index (MPI) (as a dependent variable) is related to other independent variables in addition to PCI determined from PAVER system. Other independent variables include; Cost of suitable proposed maintenance, Easiness of proposed maintenance, Average Daily Traffic (ADT) and functional classification of the roadway. An equation is developed to estimate maintenance priority index as follows:

$\mathrm{MPI}=$

$(a * P C I)-(b * C)+(c * E)+(d * A D T)\left(e * F_{0}\right.$ C. $)$

Where:

MPI: Maintenance priority index of section.

PCI: Pavement condition index of section.

$\mathrm{C}$ : cost of maintenance for each section per square meter.

E: easiness of work through maintenance sections.

ADT: Average Daily Traffic for each section.
F.C.: Functional Classifications of each section.

a,b,c,d,e: Coefficients represent the irrespective weights value for the corresponding independent variables due to experts response.

Table 1. Sample of the questionnaire for the irrespective variables affecting weights of variables for priority of pavement maintenance

\begin{tabular}{|c|c|c|c|}
\hline No. & DEFINITION & $\begin{array}{l}\text { Irres } \\
\text { pecti } \\
\text { ve } \\
\text { Weig } \\
\text { hts* }\end{array}$ & Scale Reference \\
\hline 1 & $\begin{array}{l}\text { How costly would it be to } \\
\text { implement maintenance to } \\
\text { address a good pavement } \\
\text { condition? }\end{array}$ & - & $\begin{array}{l}\text { 1. Not Costly } \\
5 \text {. Very Costly }\end{array}$ \\
\hline 2 & $\begin{array}{l}\text { What impact has PCI } \\
\text { measure on pavement } \\
\text { condition? }\end{array}$ & + & $\begin{array}{l}\text { 1.Not Impact } \\
\text { 5. Highly Impact }\end{array}$ \\
\hline 3 & $\begin{array}{l}\text { How easy would it be to } \\
\text { implement the } \\
\text { maintenance? }\end{array}$ & + & $\begin{array}{l}\text { 1. Not Easy } \\
\text { 5. Very Easy }\end{array}$ \\
\hline 4 & $\begin{array}{l}\text { What impact has the } \\
\text { functional classification } \\
\text { of the section on priority } \\
\text { of maintenance? }\end{array}$ & + & $\begin{array}{l}\text { 1. Not Impact } \\
\text { 5. Highly Impact }\end{array}$ \\
\hline 5 & $\begin{array}{l}\text { What impact has the average } \\
\text { daily traffic (ADT) on priori } \\
\text { of maintenance? }\end{array}$ & + & $\begin{array}{l}\text { 1. Not Impact } \\
\text { 5. Highly Impact }\end{array}$ \\
\hline
\end{tabular}

*Weights (from 0 to 10), Experts are asked to give the irrespective weight for each item

Statistical analysis is made for 35 questionnaire samples (sample of the questionnaire is shown in Table (I) to check the normality for data of Irrespective weights. Consequently, the average values of the irrespective weight for each variable are estimated as: $a=7.6, b=$ $6.4, \mathrm{c}=5.0, \mathrm{~d}=8.3, \mathrm{e}=6.9$.

The weights of independent variable in equation (1) are found during the inspection round of the roadway section. During the site inspection of pavement condition, data of ADT and the function classification of section roads ranking from 1 up to 5 (1:local, 2:local, distributor, 3:collector, 4:minor arterial, 5:majer arterial) are collected. Further, maintenance cost and work easiness for each distress type in flexible pavement are estimated through investigation of experience of experts for each type of maintenance process as shown in Table (II). This cost contain aftertime overlays and/or upgrading made necessary when the riding quality of pavement lowering to a definite low level of acceptability [8].

The maintenance priority of sections in study area (using data for 46 major and minor arterial sections, and 10 collector sections) is estimated by using equation (1). Plate (4) shows a layout of maintenance priority for the selected sections using GIS tools. Multiple priority 
maintenance MPI can be classified into three ranges corresponding to the scale.

On the other hand depending on MPI values and using GIS tools to layout the maintenance priority for the selected sections as shown in Plate (5).

Table 2. The maintenance cost for flexible pavement distress and work easiness

\begin{tabular}{|c|c|c|c|c|}
\hline Distress Type & $\begin{array}{c}\text { Severity } \\
\text { Levels }\end{array}$ & Description & $\begin{array}{c}\text { Financi } \\
\text { al unit } \\
\text { cost } \\
\text { (ID) }\end{array}$ & $\mathrm{E}$ \\
\hline \multirow{3}{*}{$\begin{array}{l}\text { Alligator, Block } \\
\text { Cracking, } \\
\text { Patching, } \\
\text { Potholes, } \\
\text { Depression }\end{array}$} & Low & $\begin{array}{l}\text { Surface } \\
\text { Patching }\end{array}$ & 15,000 & 4 \\
\hline & Medina & Deep Patching & 30,000 & 3 \\
\hline & High & Deep Patching & 40,000 & 2 \\
\hline \multirow{3}{*}{$\begin{array}{l}\text { Long } \\
\text {,Transverse } \\
\text {, Edge Cracking }\end{array}$} & Low & Do Nothing & 0 & 5 \\
\hline & Medina & Crack Sealing & 3,000 & 4 \\
\hline & High & $\begin{array}{l}\text { Slurry seal, } \\
\text { Thin Overlay }\end{array}$ & 15,000 & 3 \\
\hline \multirow{3}{*}{$\begin{array}{l}\text { Rutting, Shoving, } \\
\text { Swell }\end{array}$} & Low & Do Nothing & 0 & 5 \\
\hline & Medina & $\begin{array}{l}\text { Milling \& } \\
\text { Repave }\end{array}$ & 25,000 & 3 \\
\hline & High & Deep Patching & 40,000 & 2 \\
\hline \multirow{3}{*}{$\begin{array}{l}\text { Asphalt } \\
\text { Bleeding }\end{array}$} & Low & Do Nothing & 0 & 5 \\
\hline & Medina & Do Nothing & 0 & 5 \\
\hline & High & $\begin{array}{l}\text { Milling \& } \\
\text { Repave }\end{array}$ & 25,000 & 3 \\
\hline \multirow{3}{*}{$\begin{array}{l}\text { Weathering / } \\
\text { Raveling }\end{array}$} & Low & Do Nothing & 0 & 5 \\
\hline & Medina & Slurry Seal & 15,000 & 4 \\
\hline & High & Thin Overlay & 20,000 & 3 \\
\hline \multirow{3}{*}{$\begin{array}{l}\text { Bumps\& Sags } \\
\text {,Corrugations, } \\
\text { Slippage Cracks }\end{array}$} & Low & Do Nothing & 0 & 5 \\
\hline & Medina & $\begin{array}{l}\text { Surface } \\
\text { Patching }\end{array}$ & 15,000 & 4 \\
\hline & High & deep Patching & 40,000 & 2 \\
\hline \multirow{3}{*}{$\begin{array}{c}\text { Reflection } \\
\text { Cracks }\end{array}$} & Low & Do Nothing & 0 & 5 \\
\hline & Medina & Refill & 8,000 & 4 \\
\hline & High & Refill & 10,000 & 4 \\
\hline \multirow{3}{*}{$\begin{array}{l}\text { Lane/Shoulder } \\
\text { Drop }\end{array}$} & Low & Do Nothing & 0 & 5 \\
\hline & Medina & $\begin{array}{l}\text { Surface } \\
\text { Patching }\end{array}$ & 3,000 & 4 \\
\hline & High & deep Patching & 4,000 & 4 \\
\hline
\end{tabular}
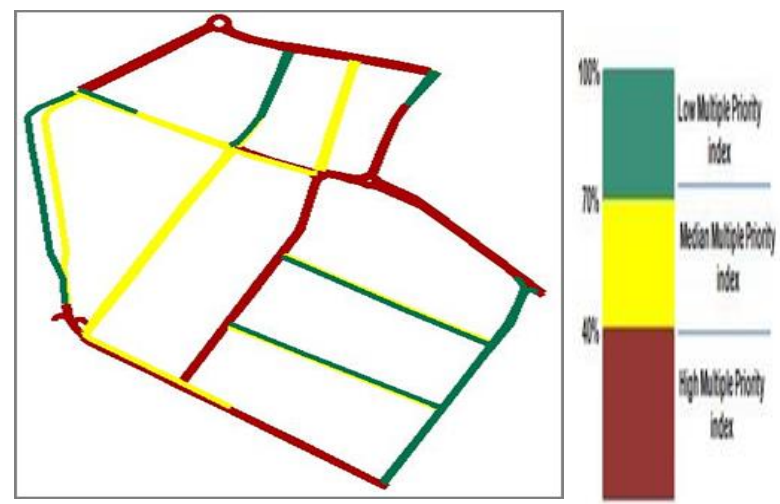

Plate 4. Priority of Maintenance and Rehabilitation Due to Multiple Priority Index for Selected Roadway Zone in Karbala City

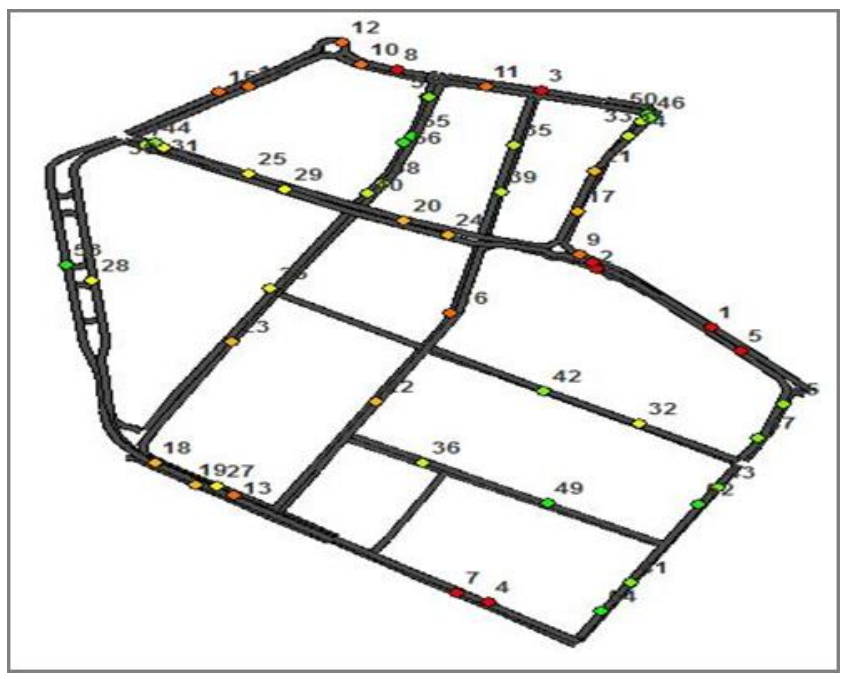

Plate 5. Sectional Maintenance Priority Layout Due to Multiple Measures for Selected Roadway Zone in Karbala City

\subsection{Incremental Benefit-Cost Method}

This method represents an extension of the benefit/cost ratio. The benefit gained from pavement maintenance is assumed to equal decrease of PCI out of hundred (100 PCI). On the other hand, the ratio of benefit to cost of pavement maintenance represents BCR depends on two variable benefit value (PCI-100). PCI determined from PAVER system, and maintenance cost of each section per square meter is estimated as explained in the multiple measure priority method. In this paper, input data (benefit and cost) are used for arterial and collector section roads (in study area). The sections are arranged depending on cost-effectiveness with (from low to high cost), a BCR greater than 1.0 in increasing order depended on their estimated cost. The section which involves with a lowest cost is listed first one. starting at the up of the list, determine the variance between the benefits of the first and second project's. Similarly determine the variance between the first and second costs of the projects.

The variance between the two values for each of benefits or cost projects are used to compute the BCR for the incremental investment by the following equation (AASHTO, 2010):

Incremental $\mathrm{BCR}=($ PVbenefits $2-$ PVbenefits 1$) /$ (PVcosts 2 - PVcosts 1)

Where:

PVbenefits 1 = Present value of benefits for lower cost of pavement maintenance.

PVbenefits 2 = Present value of benefits for higher cost pavement maintenance. 
PVcosts $1=$ Present value of cost for lower cost pavement maintenance.

PVcosts $2=$ Present value of cost for higher cost pavement maintenance.

If the incremental investment BCR is greater than 1.0, the higher cost between the two project is compared with the following project in the list. If the the incremental investment BCR is less than 1.0, the lower cost between the two project is compared with the following project in the list. Return this process. The project selected in the last pairing is considered as the best economic investment. To find the ranking of all projects, the complete evaluation is iterative without the projects already determined to be the best economic investment until the ranking of every project is determined [9].

In order to perform a most efficient and effective application of this method, MATLAB software program is developed. Furthermore, GIS Geostatic Analyses Tools is used to layout the priority result of this method as shown in Plate (6).

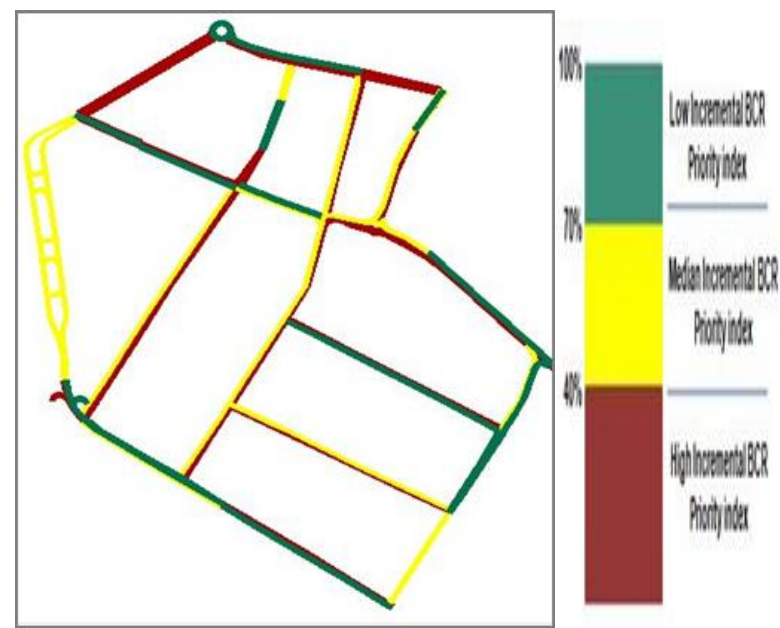

Plate 6. Priority of Maintenance and Rehabilitation Due to Incremental BCR Index for Sections of Karbala City

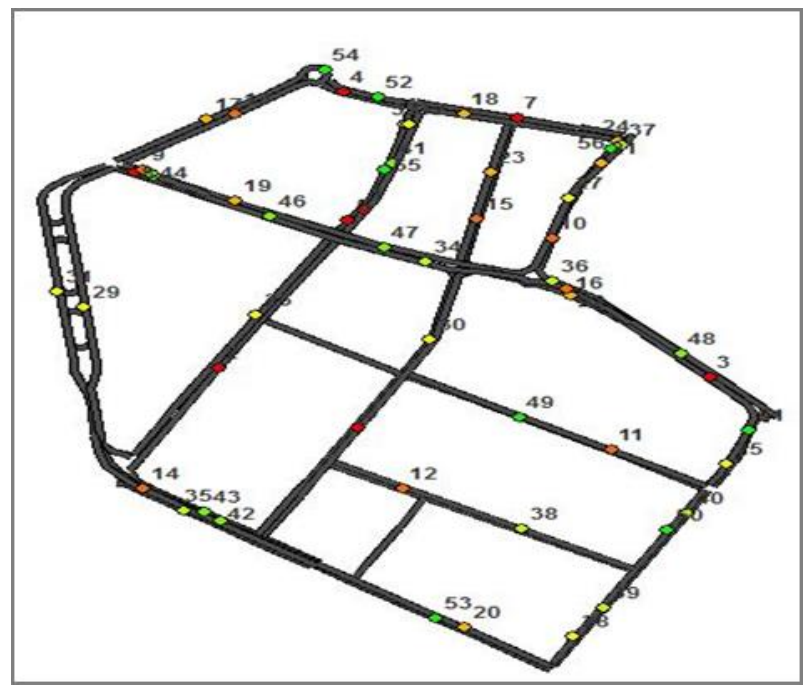

Plate 7. Sectional Maintenance Priority Layout Due to Incremental BCR Index for Sections of Karbala City
On the other hand, and depending on ranking values through incremental BCR priority index and using GIS tools to layout the maintenance priority for the selected sections as shown in Plate (7).

\section{Maintenance priority result analysis}

Maintenance priority rank result from each: PAVER PCI, matrix method, and incremental BCR method are analysis by using Wilcoxon signed-rank test (Matched Pairs Test) in SPSS software. The testing equality of means of two continuous allocation that are clearly non normal, and independent samples (i.e., there is no pairing of observations), the Wilcoxon rank-sum test or Wilcoxon two-sample test is an appropriate alternative to the two-sample [10]. The test is achieved assuming that (null hypothesis) there is no significant difference between ranking of each method of priority of maintenance. As shown in Table (III), the test shows that to a 0.05 degree of significance, there is no significant difference between rankings of each method.

Table 3. Results of Wilcoxon matched Paris test A-Descriptive Statistics

\begin{tabular}{|l|c|c|c|c|c|}
\hline & $\mathrm{N}$ & Mean & $\begin{array}{c}\text { Std. } \\
\text { Deviation }\end{array}$ & $\begin{array}{c}\text { Minimu } \\
\mathrm{m}\end{array}$ & Maximum \\
\hline PCI priority & 56 & $\begin{array}{c}28.500 \\
0\end{array}$ & 16.30951 & 1.00 & 56.00 \\
\hline EQ priority & 56 & $\begin{array}{c}28.500 \\
0\end{array}$ & 16.30951 & 1.00 & 56.00 \\
\hline BCR priority & 56 & $\begin{array}{c}28.500 \\
0\end{array}$ & 16.30951 & 1.00 & 56.00 \\
\hline
\end{tabular}

\begin{tabular}{|c|c|c|c|c|}
\hline & & $\mathrm{N}$ & Mean Rank & $\begin{array}{l}\text { Sum of } \\
\text { Ranks }\end{array}$ \\
\hline \multirow[t]{4}{*}{$\begin{array}{l}\text { EQpriority - } \\
\text { PCIpriority }\end{array}$} & $\begin{array}{l}\text { Negative } \\
\text { Ranks }\end{array}$ & $27^{\mathrm{a}}$ & 30.19 & 815.00 \\
\hline & Positive Ranks & $29^{\mathrm{b}}$ & 26.93 & 781.00 \\
\hline & Ties & $0^{\mathrm{c}}$ & & \\
\hline & Total & 56 & & \\
\hline \multirow[t]{4}{*}{$\begin{array}{l}\text { BCR_priority - } \\
\text { PCIpriority }\end{array}$} & $\begin{array}{l}\text { Negative } \\
\text { Ranks }\end{array}$ & $31^{\mathrm{d}}$ & 25.73 & 797.50 \\
\hline & Positive Ranks & $23^{\mathrm{e}}$ & 29.89 & 687.50 \\
\hline & Ties & $2^{f}$ & & \\
\hline & Total & 56 & & \\
\hline \multirow[t]{4}{*}{$\begin{array}{l}\text { BCRpriority - } \\
\text { EQpriority }\end{array}$} & $\begin{array}{l}\text { Negative } \\
\text { Ranks }\end{array}$ & $30^{\mathrm{g}}$ & 26.63 & 799.00 \\
\hline & Positive Ranks & $25^{\mathrm{h}}$ & 29.64 & 741.00 \\
\hline & Ties & $1^{\mathrm{i}}$ & & \\
\hline & Total & 56 & & \\
\hline \multicolumn{5}{|c|}{$\begin{array}{l}\text { a. EQpriority }<\text { PCIpriority } \\
\text { EQ_priority }=\text { PCI_priority }\end{array}$} \\
\hline \multicolumn{5}{|c|}{$\begin{array}{l}\text { d. BCRpriority < PCIpriority } \\
\text { BCRpriority = PCIpriority }\end{array}$} \\
\hline \multicolumn{5}{|c|}{$\begin{array}{l}\text { g. BCRpriority }<\text { EQpriority } \\
\text { BCRpriority = EQpriority }\end{array}$} \\
\hline \multicolumn{5}{|c|}{ C- Test Statistics ${ }^{\mathrm{a}}$} \\
\hline \multicolumn{2}{|c|}{\begin{tabular}{l|} 
EQpriority - \\
PCIpriority
\end{tabular}} & \multicolumn{2}{|c|}{$\begin{array}{c}\text { BCRpriority - } \\
\text { PCIpriority }\end{array}$} & $\begin{array}{c}\text { BCRpriority - } \\
\text { EQpriority }\end{array}$ \\
\hline $\mathrm{Z}$ & $-.139-^{b}$ & \multicolumn{2}{|c|}{$-.474-^{\mathrm{b}}$} & $-.243{ }^{b}$ \\
\hline
\end{tabular}




\begin{tabular}{|l|c|c|c|}
\hline $\begin{array}{c}\text { Asymp. } \\
\begin{array}{c}\text { Sig. (2- } \\
\text { tailed) }\end{array}\end{array}$ & .890 & .636 & .808 \\
\hline \\
a. Wilcoxon Signed Ranks Test & b. Based on positive ranks. \\
\hline
\end{tabular}

\section{Conclusions}

1. Depending on PAVER output integrated with GIS, the paper demonstrates two developed optimized methods of prioritization in addition to simple ranking of PAVER.

2. Investigation of expert knowledge about measures that affect prioritization of sites for maintenance results that in addition to PCI determined from PAVER system, other independent variables include; cost of suitable proposed maintenance, easiness of proposed maintenance, average daily traffic (ADT) and functional classification of the roadway.

3. The paper introduces efficient display of layout and ranking for the selected zone of roadway system based on multiple priority maintenance (MPI) index based on multiple factors affecting prioritization of sites for maintenance results.

4. The paper introduces efficient display of layout and ranking for the selected zone of roadway system based on incremental BCR priority index.

Although the two developed methods introduce different layout display for priority, statistical test shows that no significant difference between ranking of all methods of prioritization.

\section{References}

1. Vepa T.S., George K. P., and Shekharan A. R., "Prediction of Pavement Remaining Life" Transportation Research Record, No. 1524, pp 137144, 1996.

2. Bent Thagesen, Technical University of Denmark, "Highway and Traffic Engineering in Developing Countries". contact the Promotions Department, E \& FN Spon, 2-6 Boundary Row, London SE1 8HN, UK. Tel: International +44 71-865 0066, 2005.

3. NIJU.A, "GIS based Pavement Maintenance \& Management System (GPMMS)". Department of Civil Engineering, National Institute Of Technology Calicut, Calicut, Kerala 673 601, 2006.

4. Shahin, M.Y. and Walther, J.A., "Pavement Maintenance Management for Roads and Streets using the PAVER

5. Norlela I., Amiruddin I., and Riza A. , "An Overview of Expert Systems in Pavement Management", European Journal of Scientific Research ,Vol.30 No.1, pp.99-111, 2009a.

6. Washington State Department of Transportation (WSDOT), "A Guide for Local Agency Pavement Managers", Washington State Department of Transportation - Northwest Technology Transfer Center, Olympia, WA, 1994.
7. "A Best Practice For The Implementation of A Pavement Management System for Small and Medium Airport", Architectural \& Engineering Services, Civil Engineering Directorate, Airport Engineering, ATR-045, 2002.

8. American Association of State Highway and Transportation Officials (AASHTO), Guide for Design of Pavement Structures, AASHTO, Washington, D.C., 1993.

9. AASHTO, "Guide for the local calibration of the mechanistic-empirical pavement design guide". Washington, DC: American Association of State Highway and Transportation Officials, 2010.

10. Ronald E. Walpole, Raymond H. Myers, Sharon L. Myers, Keying Ye., "Probability \& Statistics for Engineers \& Scientists". Ninth Edition,University of Texas at San Antonio, 2012. 